\title{
Teachers’ Creativity in Posing Statistical Problems from Discrete Data
}

\author{
Effandi Zakaria $^{1,2}$, Faridah Salleh ${ }^{1}$ \\ ${ }^{1}$ Department of Methodology and Educational Practice, Faculty of Education, Universiti Kebangsaan Malaysia, \\ Bangi, Malaysia \\ ${ }^{2}$ Institute of Space Science, Universiti Kebangsaan Malaysia, Bangi, Malaysia \\ Email: effandi@ukm.my
}

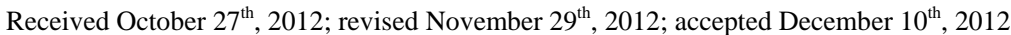

\begin{abstract}
Choosing a quality problem in mathematics is a challenge for many teachers. Teachers cannot rely on textbooks for good problems. They have to be able to pose their own problems in order to promote mathematical thinking among students. This study was conducted to explore the creativity of 175 teachers in terms of fluency, flexibility, and originality in posing statistical problems. Participants consisted of secondary school teachers from twenty schools in Peninsular Malaysia. Teaching experience was ranged from 1 to 33 years. The features of the problems posed by these teachers were also studied. The participants were provided a stimulus, which was a set of ungrouped discrete data, and they were asked to pose as many problems as they could. The posed statistical problems were supposed to promote mathematical thinking and to increase students' understanding. Findings showed that participants were able to pose a total of 270 (74\%) statistical problems within the time given. The mean of the creativity score was 11.08 $(\mathrm{s} . \mathrm{d} .=6.76)$. Analysis showed no significant difference in creativity between gender and the value of $\mathrm{t}=$ $-.346, p=.73$, where $p>.05$. Analysis showed significant differences in the teachers' creativity scores for three groups of teachers: $\mathrm{F}(2172)=6.83, p=.001, p<.05$. The results also showed that $115(31.5 \%)$ posed problems focuses on the statistical content measure of central tendency. The study provided exposure to the teachers to pose problems that can trigger students' thinking in solving statistical problems.
\end{abstract}

Keywords: Statistical Problems; Creativity; Fluency; Flexibility; Originality

\section{Introduction}

NCTM (2000) has strongly recommended both problem posing and problem solving activities are implemented in the teaching and learning of mathematics. The quality of the problems can serve as an index of how well a person can solve problems (Kilpatrick, 1987). Gonzales (1996) found that there was a correlation between mathematical competence and problem posing. Therefore, teachers should have skills in both posing problems and solving problems in order to help students to learn mathematics (Brown \& Walter, 1983; Kilpatrick, 1987; Silver, 1994).

Problem posing is a creation of a new problem or the reformulation of problem through a given situation (Leung, 1993). Problem posing also involve the generation of new problems or questions in order to explore a given situation as specially as a complex problem (Silver, 1994) In posing new problems, the emphasis is not to produce solutions but the structure of the problems itself (Lowrie, 2002). A study by Silver et al. (1996) shows that the activity of problem posing can be done either during the process of problem-solving or after the process of problem solving. According to Chua (2004), Jensen (1973), and Noraini (2001), Guilford and Torrance have identified four types of creative thinking: 1 ) originality, which is the process of creating new ideas and original; 2) fluency, which is the process of creating a lot of ideas at one time, where the generated ideas do not necessarily to be too different; 3) flexibility, which is the process of producing a range of ideas and different category altogether; and 4) elaboration, which is the process of adding one idea to another idea or process to see something in detail. Balka (1974) used to measure creativity in mathematics in terms of their fluency, flexibility, and the originality of posed problems.

Several studies found that mathematics instruction is still using the traditional methods (Tengku Zawawi, 2005; TIMSS, 2007; Yusminah, 2009; Zakaria \& Iksan, 2007). In fact, according to Tengku Zawawi (2005) and Yusminah (2009), teachers are not able convey knowledge and conceptual skills to students effectively. Students were less active in teaching and learning process due to the teacher-centered approach. Student interaction with and among teachers is quite limited. Students prefer to listen for information without making any contribution. They are not willing to ask or to give an opinion (Ministry of Malaysian Education, 2008). Furthermore, Cunningham (2004) states that student serve mostly as listeners and have little responsibility for constructing their own knowledge during lessons. Promoting posing problems in class would give students the experience of having a series of related problems per each topic. As teachers become proficient in problem posing, they will be more willing to have their students engage in such activities (Silver et al., 1996). Students would be able to form and to develop their skills to identify strategies that provide solutions to the problems. According to Perez (1985), research shows that, if students are able to pose a good problem, then the probability that they can solve problems is high. Understanding of mathematical concepts learned by the students can be shown through the works from problem-generating activities (English, 1997; Stickles, 2006). 
NCTM (2000) suggested that all students should have knowledge of statistics so that it was not limited to a group who were interested to conduct research only. Initiatives to improve teaching and learning of statistics and probability have been highlighted by the document of NCTM since 1989. More emphasis should be given to these issues so that students can apply the skills in data handling (Brumbaugh \& Rock, 2006). However, this topic is often not taught widely. Studies conducted in the US shows that high school students said they get little exposure or indirectly exposed to the topics of statistics or probability (Brumbaugh \& Rock, 2006).

According to the study by Leung and Silver (1997), pre-service teachers were able to pose mathematical problems, but mostly their problems were lacking in mathematical complexity, while Crespo (1998) shows that teachers need experience to pose problems so that they can create a good and challenge problems. Giving an original problem to students to solve would be the most effective way to teach mathematics (Perrin, 2007).

Skill in posing statistical problems should be seen as an approach to identify how teachers are able to pose good problems and use the information from environment that leads to creative thinking. The ability to pose a variety of good problems can improve self-confidence in promoting the posing activities in class (Stickles, 2006). To pose a problem requires active thinking processes. A stimulus is needed as a trigger for the ideas (Slavin, 2000). In this study, a stimulus, which was the ungrouped discrete data, was given to teachers. There were five steps involved in the process of posing statistical problems. First, a problem poser would try to identify the problem by looking at the information available to suit his/her goal. Second, the poser would identify the source of the problem. In the third step, the problem poser determined what was required for the cognitive domain of thinking, such as the level of knowledge, understanding, or even evaluating (Winograd, 1991). The fourth step carried out posing an interesting problem (Grundmeier, 2003). Finally, the fifth step was checking or looking back at what had been done (Polya, 1973).

In this study, statistical creativity was measured in terms of fluency, flexibility, and originality of the problems (Balka, 1974). The fluency of the problem refers to the number of problems that can be posed in a certain time, not the quality of ideas that are emphasized. Flexibility refers to the number of posed problems different from the quality within the posed problem. Originality refers to uncommon posed problems between participants. Problems features referred to the content of the statistical syllabus of Mathematics Lower Secondary and Upper Secondary, including Additional Mathematics. The features also referred to the cognitive level of Bloom's taxonomy (Bloom, 1976) which refers to the six levels of cognitive skills needed in teaching and learning mathematics. The hierarchy is arranged from the lower level of thinking to the highest level of thinking, as follows: remembering, understanding, applying, analysing, synthesis, and creating (Anderson \& Krathwohl, 2001).

The purpose of the study was to identify the creativity of statistical problems in terms of fluency, flexibility, and originality. In addition, this study also tried to identify the features of the posed problem. Specifically, the objectives of this study were as follows:

1) To identify the features of the posed problems among teachers in terms of statistical content.

2) To determine whether there were any statistically significant differences in creativity to pose problem among teachers according to their teaching experience.

\section{Methodology}

This study involved a total of 175 mathematics teachers from twenty schools in Peninsular Malaysia. Samples of this study were carried out randomly. Teaching experience of these teachers was ranged from 1 to 33 years. All of them had experience in teaching mathematics and Additional Mathematics. There were several new teachers who had taught less than a year, but they had received in-house training from time to time. Data was collected by the researcher from each school at the selected time. A written instrument was used to collect posing problems. This instrument included a stimulus consisting of 20 ungrouped discrete data. Before the study was conducted, the teachers involved were informed. Through the given stimulus, teachers were asked to pose as many statistical problems that can trigger students to think creatively. The problems were not evaluated for their solution, but for activities that increase the understanding in learning a particular topic. Teachers were reminded that they did not need to solve the posed problems. Teachers were given 20 minutes to carry out their tasks. The posed problems were analyzed in three steps. The first step was to identify whether the problem can be solved. This was due to the logical problem and covered the content in the syllabus. The second step was to identify the statistical content, and the third step was given a score of fluency, flexibility, and the originality of the problem in accordance with a rubric.

\section{Findings and Discussion}

The first finding concerns the features of posed problems among teachers in terms of statistical content to answer the research question, "What are the features of the posed problem in terms of the statistical content?" The answers are provided in Table 1, which shows the distribution of statistical problems by category.

Statistical content is divided into five sub-categories: content; basic statistics such as frequency, score/value, percentage, ratio, interval classes, class size, frequency tables; measure of central tendency which consists of the mean, mode, median; dispersion measurement which consists of range, quartile range, standard deviation, variance; cumulative frequency tables, bar graphs, line graphs, pie charts, histograms, frequency polygon, ogive; an opinion, conclusion/summary.

Teachers had posed a total of 365 problems, but after the analysis only 270 (74\%) was categorized as a statistical problem. The problem posed by these teachers, mostly centered on the one sub-main statistical content with 173 (47.4\%) problems. The percentage was highest in the central measurement, 115 (31.5\%) problems. A total of 71 (19.5\%) posed problems were the combination of two sub-content. For example, there were $40(11.0 \%)$ posed problems in the category of "The combination of BS and one of the CT, DM, CG, and OC”. While only $26(7.1 \%)$ of the posed problems were a combination of three sub-contents. The posed problems that involved student opinions, making conclusions, and discussion were very limited. For example, in the main categories of sub-content, only 5 (1.4\%) problems posed in the "OC" category. A total of 30 (8.2\%) of the problems for "The combination of CT and one of the DM, CG, OC” were in two sub-content category, and only 1 (.3\%) problem was in the category of "The combination of CT 
Table 1.

Number of problems according to categories of statistical content.

\begin{tabular}{lll}
\hline \multicolumn{1}{c}{ Statistical content category } & \multicolumn{1}{c}{ Number of problems } \\
\hline 5sub-main content & Basic statistics (BS) & $36(9.9 \%)$ \\
& Central of tendency (CT) & $115(31.5 \%)$ \\
& Dispersion measurement (DM) & $14(3.8 \%)$ \\
& Charts and graphs (CG) & $3(.8 \%)$ \\
& Opinions and conclusions (OC) & $5(1.4 \%)$ \\
The combination of two sub-content & & $40(11.0 \%)$ \\
& BS and one of the CT, DM, CG, OC & $30(8.2 \%)$ \\
& CT and one of DM, CG, OC & $1(.3 \%)$ \\
The combination of 3 sub-content & DM \& OC & $19(5.2 \%)$ \\
& & $7(1.9 \%)$ \\
Unaccepted problems & BS with any 2 from CT, DM, CG, OC & $95(26.0 \%)$ \\
Total & CT with any 2 of the DM, CG, OC & 365 \\
\hline
\end{tabular}

\& OC”. While the combinations of three sub-contents were from category "The combination of KMS with any 2 of the KMP, C \& G, P \& K,” only seven (1.9\%) problems were posed.

The following are examples of posed problems:

- Example 1:

"The data above represent number of goals by a football team for 1 season. What is the average goal for the football team for that season?"

- Example 2:

"Data below represent the number of books read by 20 students in January 2011.

1) Construct a frequency table for the given data.

2) By using data from 1), draw a pie chart to represents the data.

3) State the mode for the number of books read."

- Example 3:

"The above data shows the number of children of a group of staff in an office. Find:

1) The mean number of children of the staff.

2) The standard deviation of children of the staff."

This study shows that even if teachers were asked to pose problems that lead to higher-order thinking, some teachers posed problems in the lower category (Table 2). Percentages of $18.1 \%$ (66 problems) on understanding level, 48.5\% (177 problems) on applying level and only $7.4 \%$ (27 problems) on analysing level. A study by Senk et al. (1997) found that $68 \%$ of posed problems were in low-level category, While, Harpster (1999) found that $60 \%$ of the teachers posed low-level problems. According to Thompson (2008), even if the teacher can identify the problem in the form of low-level thinking or higher-order thinking (HOT), but, when they were asked to pose problems of higher-order thinking, only $45 \%$ of teachers will posed higher-level problems. Most of the teacher's experienced this problem posing activity for the first time. The teachers were used to creating test questions by reformulating problems that were commonly found in the textbook or in references. This is in line with the findings of Lowrie (2002), in which the inclination problems generated for the first time will usually be similar to exercise or routine problems. Therefore, the consistency of posing problems was essential. A study by Cespo (2003) found that teachers can change the patterns of posed problems and become better quality problem posers if they do this activity often.
Table 2.

Category of bloom taxonomy.

\begin{tabular}{cc}
\hline Level of taxonomy Bloom & Task \\
\hline Understanding & $66(18.1 \%)$ \\
Applying & $177(48.5 \%)$ \\
Analysing & $27(7.4 \%)$ \\
Unaccepted problems & $95(26.0 \%)$ \\
Total & $365(100 \%)$ \\
\hline
\end{tabular}

The second research question: "Are there any statistically significant differences in creativity to generate problem among teachers according to teaching experience?” Table $\mathbf{3}$ showed the summary for one way between-groups ANOVA.

Testing for homogeneity of variance for the three groups showed the values of the Levene's $=1.258$ (Sig. $=.287$ ), which is $>.05$. ANOVA analysis was used to explore the impact of teachers' experience in creativity scores through the ungrouped discrete data. Teachers were grouped into three groups according to years of teaching (group 1: less than 6 years; group 2: 6 to 10 years; group 3: more than 10 years). Analysis showed significant differences at $p<.05$ in creativity scores for three groups of teachers: F (2172) $=6.83, p=.001$. Post-hoc comparisons using the Turkey HSD test showed a group 1 mean score $(\mathrm{M}=8.53, \mathrm{SD}=5.85)$ were significantly different from group 3 $(\mathrm{M}=13.15, \mathrm{SD}=6.94)$. Group $2(\mathrm{M}=10.59, \mathrm{SD}=6.53) \mathrm{did}$ not differ significantly from group 1 or group 3 . Experience teachers $(>10 \mathrm{yrs})$ are more creative in generating problems than other teachers. This may be due to the exposure to more statistical knowledge during their teaching career.

\section{Conclusion}

Teachers who participated in this study were asked to pose a statistical problem. However, from 365 posed problems, only 270 (74\%) problems were accepted for this study. The excluded problems were not logical, did not have a solution, or were incomplete. The features posed problems were identified in terms of statistical content. The findings showed that not all teachers tend to posed higher-order thinking problems. There were differences in terms of experience; the differences between the group of teachers whose experience ranged fewer than six years and other groups were clearly shown. 
Table 3.

One way between-groups ANOVA in creativity scores based on teachers' experience.

\begin{tabular}{cccccc}
\hline Variables & Teaching experience & N & Mean & F & $\boldsymbol{p}$ \\
\hline Teachers' creativity & K1: $<6$ yrs & 43 & 8.53 & 6.831 & .001 \\
K2: $6-10$ yrs & 64 & 10.59 & & \\
& & & & \\
K3: $>10$ yrs & 68 & 13.15 & \\
\hline
\end{tabular}

Teachers should be exposed to problem-generating activities before they can perform this activity with students. Teachers should engage students in class to participate in problem-posing (Zakaria \& Ngah, 2011). Creating a new problem or reformulating a problem is not an easy task, and it requires planning, skill, and personal strength to do this activity effectively. Previous studies have shown that problem posing can increase students' comprehension, encourage communication of mathematics, improve students' self-confidence, and establish positive attitudes towards mathematics. Problem posing should be given serious consideration by teachers in preparing lesson activities.

\section{REFERENCES}

Anderson, L. W., \& Krathwohl, D. R. (Eds.) (2001). A taxonomy for Learning, teaching, and assessing: A revision of Bloom's taxonomy of educational objectives. New York: Addison Wesley Longman.

Balka, D. S. (1974). The development of an instrument to measure creative ability in mathematics. Ph.D. Thesis, Main St. Durham, NH: University of New Hampshire.

Bloom, B. S. (1976). Human characteristics and school learning. New York: McGraw-Hill.

Brown, S. I., \& Walter. M. I. (1983). The art of problem posing. Philadelphia: The Franklin Institute Press.

Brumbaugh, D. K., \& Rock, D. (2006). Teaching secondary mathematics (3th ed.). Hillsdale, NJ: Lawrence Erlbaum Associates.

Chua, Y. P. (2004). Creative and critical thinking styles. New York: University Putra Malaysia Press.

Crespo, S. (2003). Learning to pose mathematical problems: Exploring changes in preservice teachers' practices. Educational Studies in Mathematics, 52, 243-270. doi:10.1023/A:1024364304664

Cunningham, R. F. (2004). Problem posing: An opportunity for increasing students responsibility. Mathematics and Computer Education, 38, 83-89

English, L. D. (1997). Promoting a problem posing classroom. Teaching Children mathematics, 4, 172-180

Gonzales, N. A. (1996). Problem formulation: Insights from student generated questions. School Science and Mathematics, 96, 152-157. doi:10.1111/j.1949-8594.1996.tb15830.x

Grundmeier, T. A. (2002). University students' problem posing and attitudes towards mathematics. Primus: Problem, Resources, and Issues in Mathematics Undergraduate Studies, 12, 122-134.

Grundmeier, T. A. (2003). The effects of mathematical problem posing providing experiences for $k-8$ pre-service teachers: Investigating teachers' beliefs and characteristics of posed problems. Ph.D. Thesis, Main St. Durham, NH: Universty of New Hampshire.

Harpster, D. L. (1999). A study of possible factors that influence the construction of teacher-made problem that assess higher-order thinking skill. Ph.D. Thesis, Bozeman: Montana State University.

Jensen, L. R. (1973). The relationships among mathematical creativity, numerical aptitute and mathematical achievement. Ph.D. Thesis. Austin: University of Texas.

Kilpatrick, J. (1987). Formulating the problem: Where do good problems come from? In A. H. Schoenfeld (Ed.), Cognitive Science and Mathematics Education (pp. 123-147). Hillsdale, NJ: Lawrence Erlbaum Associates.

Leung, S. S. (1993). Mathematical problem posing: The influence of task formats, mathematics knowledge, and creative thinking. In I.
Hirabayashi, N. Nohda, k. Shigematsu, \& F. Lin (Eds.), Proceedings of 17th International conference of International Group for the Psychology of Mathematics Education (pp. 33-40). Tsukuba, Japan.

Leung, S. K., \& Silver, E. A. (1997). The role of task format, mathematics knowledge, and creative thinking on the arithmetic problem posing of prospective elementary school teachers. Mathematics Education Research Journal, 9, 5-24. doi:10.1007/BF03217299

Lowrie, T. (2002). Designing a framework for problem posing young children generating open-ended task. Contemporary Issues in Early Childhood, 3, 354-364. doi:10.2304/ciec.2002.3.3.4

Ministry of Malaysian Education (2008). Inspectorate and quality assurance. Annual Report, Putra Jaya.

NCTM (2000). Principles and Standards for School Mathematics. Reston, VA: NCTM.

Noraini, I. (2001). Pedagogy in mathematics education. Kuala Lumpur: Utusan Publications \& Distributors Sdn Bhd.

Perez, J. A. (1985). Effects of students generated problems on problem solving performance (writing word problems). Ph.D. Thesis, New York: Columbia University College.

Perrin, J. R. (2007). Problem posing at all levels in the calculus classroom. School Science and Mathematics, 107, 182-192. doi:10.1111/j.1949-8594.2007.tb17782.x

Polya, G. (1973). How to solve it: A new aspect of mathematical method (2nd ed.). Princeton, New Jersey: Princeton Univeversity Press.

Senk, S. L., Beckmann, C. E., \& Thompson, D. R. (1997). Assessment and grading in high school mathematics classroom. Journal for Research in Mathematics Education, 28, 187-215. doi:10.2307/749761

Silver, E. A. (1994). On mathematical problem posing. For the Learning of Mathematics, 14, 19-28.

Silver. E. A., Mamona-Downs, J., Leung, S. S., \& Kenney, P. A. (1996). Posing mathematical problems: An exploratory study. Journal for Research in Mathematics Education, 27, 293-309. doi: $10.2307 / 749366$

Slavin, R. E. (2000). Educational psychology: Theory and practice (6th ed.). Boston: Allyn \& Bacon.

Stickles, P. R. (2006). An analysis of secondary and middle school teachers' mathematical problem posing. Ph.D. Thesis, Bloomington: University of Indiana.

Tengku Zawawi, T. Z. (2005). Pedagogical content knowledge of fraction among primary school mathematics teacher. Ph.D. Thesis, Bangi: Faculty of Education, Universiti Kebangsaan Malaysia.

TIMSS (2007). International mathematics report. Boston: International Study Center.

Thompson, T. (2008). Mathematics teachers' interpretation of higherorder thinking in Bloom's taxomomy. Electronic International Journal of Mathematics Education, 3, 96-109.

Winograd, K. (1991). Writing, solving and sharing original math story problem. Case studies of fifth grade children's cognitive behaviour. The Annual Meeting of the American Educational Research Association, Chicago, 3-7 April 1991.

Yusminah, M. Y. (2009). A case study of teachers' pedagogical content knowledge of functions. Proceedings of the 3th International Conference on Science and Mathematics Education. Penang, 10-12 November 2009

Zakaria, E., \& Iksan, Z. (2007). Promoting cooperative learning. Eurasia Journal of Mathematics, Science \& Technology Education, 3, 35- 39.

Zakaria, E., \& Ngah, N. (2011). A preliminary analysis of students' problem-posing ability and its relationship to attitudes towards problem solving. Research Journal of Applied Sciences, Engineering and Technology, 3, 866-870. 